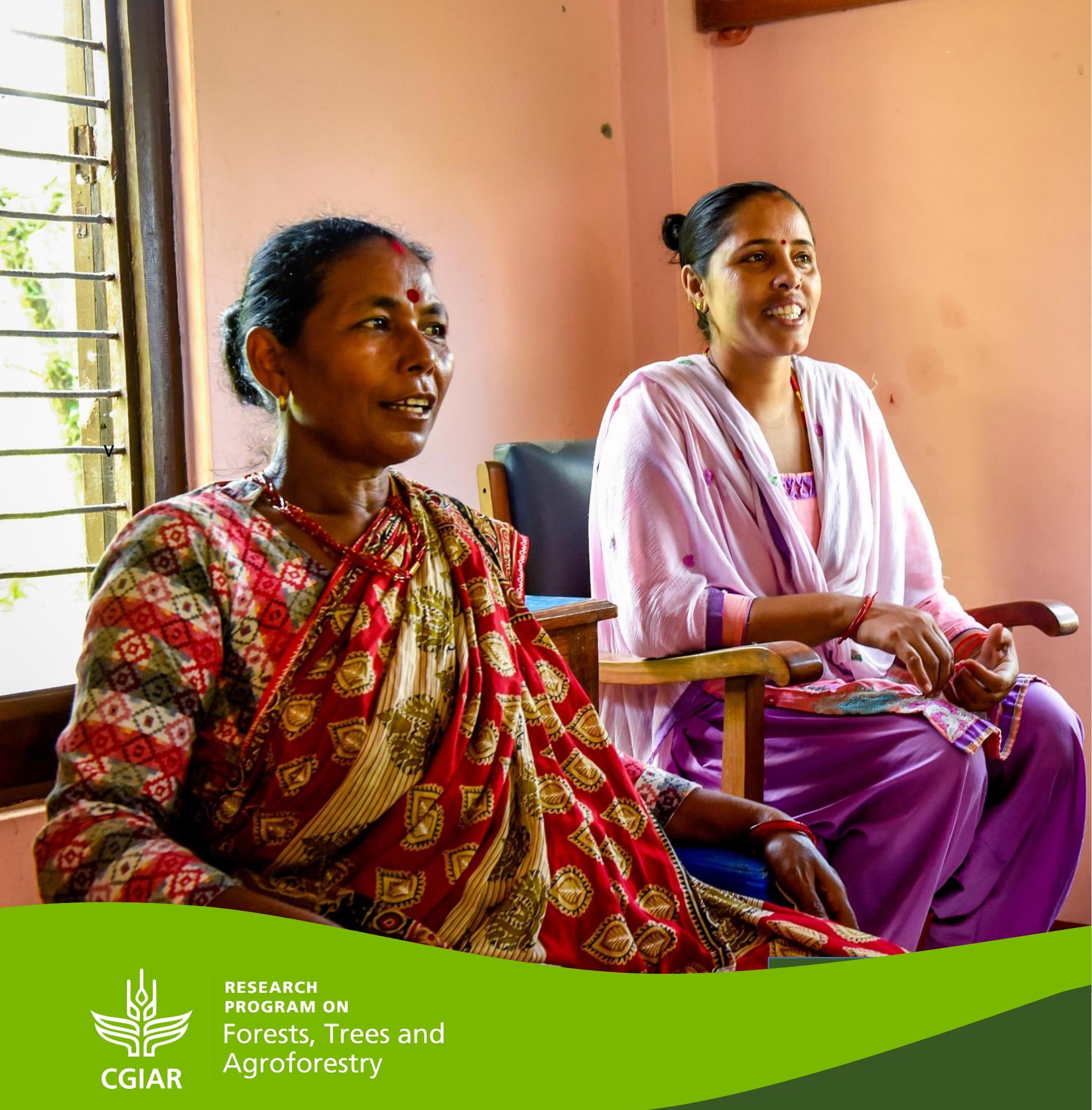




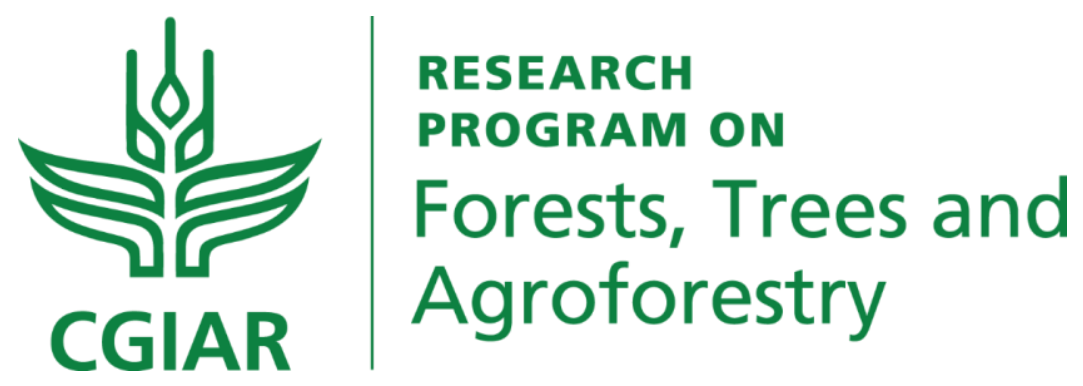

\section{Gender Equality and Social Inclusion}

A Revised Agenda and Action Plan for the CGIAR Research Program on Forests, Trees and Agroforestry 2020-2021 


\section{Contents}

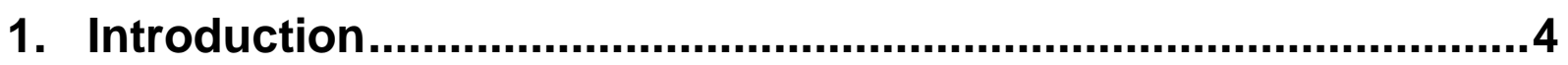

2. Rationale: Gender in forests and agroforestry ...........................5

3. Goals and approach of FTA's gender and social inclusion

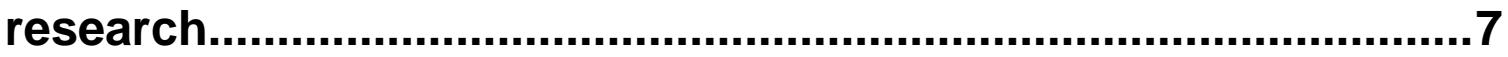

4. Gender and social inclusion research agenda ..........................10

5. Where gender meets generation: Engaging with youth in rural landscapes .................................................................14

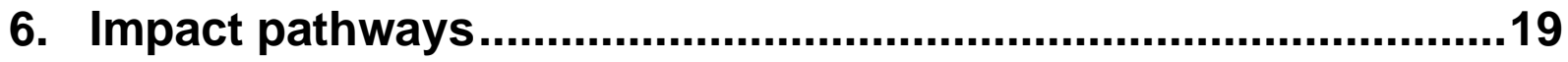

References …..................................................................................21

Annex 1 Key youth-related research questions for FTA.................25

Annex 2 Gender research embedded in FTA's operational priorities 


\section{Introduction}

The CGIAR Research Program (CRP) on Forests, Trees and Agroforestry (FTA) focuses on enhancing livelihoods through forest, tree, and agroforestry systems, and improving and protecting natural resources. With an estimated 1.6 billion people dependent on forests and trees, including trees on farms, for their livelihoods, forest, tree and agroforestry systems have much to contribute to addressing inequalities between women and men, and empowering disadvantaged women in ways that contribute to sustainable landscapes. FTA's Gender Strategy (2013) outlined the critical roles both women and men play in managing forests, agroforestry and tree resources across the developing world, illuminating the missed opportunities to generate knowledge that can guide the redressing of gender inequities in accessing resources and benefits. It recognized the need to achieve greater gender equity as a goal in its own right, and as a means for more effective natural resource management (NRM).

As FTA's research agenda has evolved since the program's inception, so too has the program's portfolio of gender and social inclusion research. This revised research agenda and action plan draws on a tradition of quality gender work within FTA centers and complements FTA's original Gender Strategy (2013). It reflects the evolution of the program, including thematic and methodological developments in gender research and praxis, and increases the focus on the nexus of gender and generation (including youth issues), and efforts to make FTA's research increasingly transformative. 


\section{Rationale: Gender in forests and agroforestry}

Both women and men depend on forests, agroforestry and trees for their livelihoods, and play a critical role in managing them. However, inequalities persist in roles, rights and responsibilities of women and men, and shape the ways they participate in decision making, benefit from forest and tree resources, and experience changes in forest and tree-based landscapes. Gender biases in the wider policy environment and exclusionary social norms result in a gender gap in access to and control of assets and key resources, including land, labor, credit, information and extension services, with women facing disadvantages in several domains (World Bank et al. 2009; FAO 2011). The different cultural, domestic and economic roles that women and men play in their households and communities influence the sets of knowledge and priorities they develop about and for forest and tree resources and the environment (Bee 2016). Gender intersects with other factors of social differentiation, such as age or generation, socioeconomic status and ethnicity, to influence local women's and men's experiences, opportunities and constraints in forest and agroforestry landscapes (Colfer et al. 2018).

Gender norms and other social structures that mediate women's and men's roles and relations are manifest in many areas of concern to FTA. For example, they lead to women's underrepresentation in forest landscape governance, including in forest user groups (Sunderland et al. 2014), and hinder women's active participation and influence in such groups, even when they are formally represented (Agarwal 2010; Sun et al. 2011). Such processes can dissuade women and other excluded groups from adhering to collective forest management rules that have been established without their consent, and may run counter to their needs and purposes. In contrast, women's active participation in forest governance can promote sustainable management practices and improved forest incomes (Agarwal 2010; Mwangi et al. 2011; Coleman and Mwangi 2013).

Forest and landscape restoration efforts face similar challenges in meaningfully engaging local people in ways that safeguard their rights and advance their different needs and interests. Women and marginalized groups are particularly susceptible to exclusion from decision-making and benefit-sharing processes, as even in wellintentioned restoration initiatives, participation tends to be dominated by better resourced, formally educated, land-owning men from privileged sociocultural groups (Nederlof and Dangbégnon 2007; McLain et al. 2018). Initiatives that do not actively seek to protect the rights and promote the voices of marginalized groups may, in fact, reinforce social cleavages (McDermott 2008), and ultimately undermine the legitimacy and efficacy of restoration efforts. For instance, benefit schemes based on land ownership (UNEP et al. 2011) or relative contributions of land to restoration (Agarwal 2001) may have significant gender implications, as women in many parts of the world control less land than their male counterparts.

Gender norms and power relations also shape the nature and extent of women's and men's participation in forest, tree and agroforestry value chains and their accrued benefits. Generally, rural women - relative to men - are confined to less profitable value chains (Ingram et al. 2014), occupy less remunerative nodes in a given value chain (such as harvesting and retailing) and run smaller businesses (Ingram et al. 2016). Women are often 'shadow workers', whose unpaid contributions to the production processes are not recognized, even in more formalized value chains, such as oil palm and furniture value chains in Indonesia (Sijapati et al. 2016). Yet, as forest, tree and agroforestry value chains become integrated into national and global economies, changes in the availability and profitability of tree products affect the 
gendered dynamics and distribution of benefits along certain chains. Growing demand for charcoal in Zambia, for example, has opened up spaces for women to participate in the traditionally male-dominated value chain (Gumbo et al. 2013). Such opportunities may challenge unequal gender relations by altering perceptions about men's and women's work and enhancing women's economic empowerment (Barrientos 2001). However, they also entail risks, such as elite or corporate appropriation of traditionally female products or value chains as their profitability increases (Ingram et al. 2014; Turner 2014).

Gender gaps in access to and control of assets and resources, the gender division of labor and gendered knowledge influence adaptive capacities and strategies in the face of climate change and a changing natural resource base (Djoudi and Brockhaus 2011). Gender inequalities and norms limiting women's access to and control of resources, such as land, capital and technical services, can hinder their capacity to navigate the challenges of a changing climate (Brody et al. 2008; Lambrou and Piana 2006; Rodenberg 2009). Climate change coupled with several processes of rural transformation are manifest in migration and multi-local livelihoods, which have corollary effects on gendered and generational labor and employment, decision making and resource allocation patterns (Djoudi and Brockhaus 2011).

The aforementioned inequalities, embedded in formal and informal institutions and structures, hinder the change needed to support the sustainable and equitable development solutions that FTA seeks to deliver. Hence, FTA seeks to understand and develop an empirical evidence base on the structural barriers that (re)produce gender inequalities in forest and agroforest landscapes, with a focus on governance, migration and multi-local livelihoods, tenure, restoration, climate change and value chains. It also seeks to develop innovations to transform discriminatory structures and norms to achieve equitable (gender-transformative) outcomes, including gender equality and social inclusion in their own right. 


\section{Goals and approach of FTA's gender and social inclusion research}

Building on experience to date in gender research and efforts to strengthen gender integration across program activities and processes, FTA has broadened its research and action focus to: adopt a more sophisticated and nuanced understanding of gender issues, placing greater emphasis on intersectionality, including the nexus between gender and generation (with a focus on youth); prioritize transformative gender work; adopt innovative and mixed methods - including participatory action research - in research and evaluations; incorporate the latest thinking on gender and development in capacity-building efforts; enhance learning through the creation of knowledge-sharing platforms; broaden and deepen its outreach and partnerships; and enhance gender integration in monitoring and evaluation frameworks.

FTA prioritizes a transformative approach that aims to challenge the underlying causes of gender inequality, such as norms, relations and institutional structures that perpetuate discrimination and imbalances, rather than merely addressing its symptoms (e.g. unequal income, different needs and preferences) (Cole et al. 2014; Hillenbrand et al. 2015). Such an approach seeks to achieve more equitable involvement of women and girls in decision making, control of resources, and control over their own labor and destiny. The transformation that is sought is deep, lasting and pervasive, moving beyond individual self-improvement among women toward transforming the power dynamics and structures that affect men's and women's capacities to: (i) control assets and resources; (ii) value and distribute unremunerated labor; and (iii) meaningfully participate in decision making at the household and community levels, and beyond. The aim is to develop innovations to increase women's voice and influence, foster gender equality and social inclusion, and enable both women and men across scales to empower themselves.

FTA recognizes gender equality as an inherent human right. Hence, responsiveness to gender across the FTA portfolio is seen as holding intrinsic rather than merely instrumental value (i.e. equality is not seen primarily as a mechanism to deliver greater impact, but as a fundamental right). This entails a need to recognize that while win-win outcomes are optimal, gender equality and other objectives may at times need to be reconciled.

The program adopts an intersectionality lens to analyze how gender intersects with other factors of social differentiation, such as socioeconomic status or ethnicity, to shape livelihood and resource management decisions, governance and the distribution of benefits from tree-based systems. Explicit attention is directed to how gender intersects with age, generation or stage in the life cycle (see section 6 on youth). Hence, the social transformation sought moves beyond gender, to encompass other dimensions of social inclusion. FTA envisions that systematic social analyses will provide scope for locating the most salient features of disadvantage in specific research settings and ensuring their inclusion in the research and action process.

Notably, FTA works in dynamic contexts, where not only forest landscapes but also the ambitions, interests and livelihood opportunities of younger generations are rapidly changing. Explicitly considering such intergenerational changes and how they link with gender and other factors of social differentiation helps recognize the current (and future) challenges and opportunities for young people in FTA program areas. Therefore, FTA conducts research with younger generations, and about young people's actual 
and desired engagement in forest and tree-based landscapes to enhance opportunities for young women and men.

FTA views gender integration in research as a fundamental part of doing good science (European Commission 2011), and approaches gender as a theme that cuts across every aspect of the FTA research portfolio. In so doing, it contributes to FTA's Intermediate Development Outcomes (IDO) and to global efforts to 'Achieve gender equality and empower all women and girls' (Sustainable Development Goal 5). This research and action plan lays out the pathways through which FTA contributes to the CGIAR IDO 'Equity and inclusion achieved (gender and youth)' and its three sub-IDOs: gender-equitable control of productive assets and resources; development and dissemination of technologies that reduce women's labor and energy expenditure; and improved capacity of women and young people to participate in decision making.

The FTA Gender Strategy follows a multi-pronged approach, characterized by two main, mutually supportive strands of work. The first strand centers on knowledge generation and delivering quality gender, social inclusion and youth research (detailed in sections 4 and 5 below). The second strand focuses on strengthening gender integration along FTA's impact pathways, including how the program engages with a wide range of stakeholders (detailed in section 6).

Figure 1 depicts how the two strands interact, and how impactful research in FTA is influenced by stakeholder engagement, including in the early stages of the research process. The two strands are mutually supported as an enabling environment for gender research (strand 2), which nurtures researcher capacities and motivations to undertake gender(-responsive) research underpins knowledge generation (strand 1). 


\section{Figure 1 Theory of change of gender integration in FTA}

\section{Strand 1}

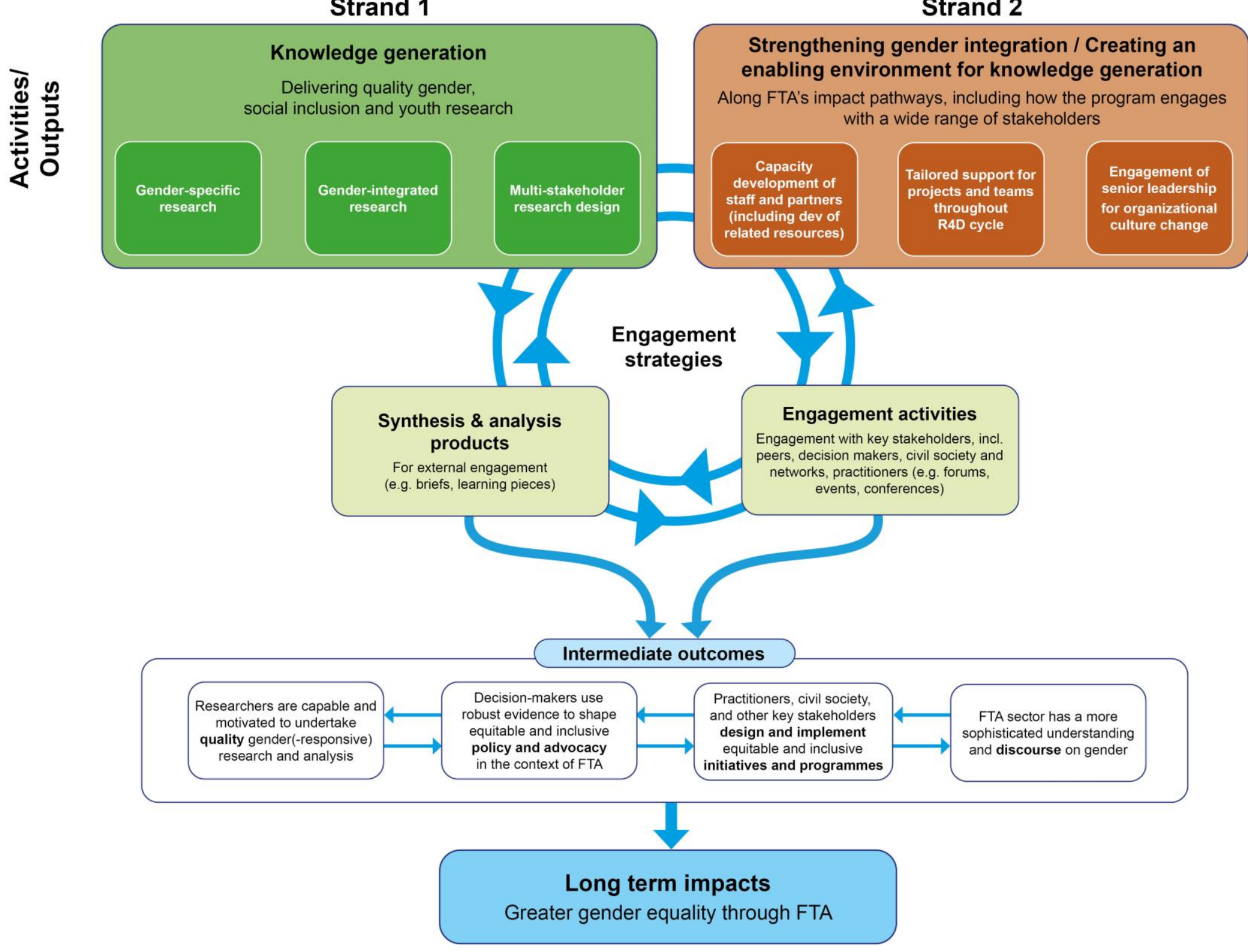




\section{Gender and social inclusion research agenda}

FTA's gender research explores the gender norms, institutions and power relations that represent structural barriers to gender equality, and ways to redress these to enable transformative change toward more equitable and sustainable forest, tree and agroforestry systems. To achieve this, FTA's research portfolio includes genderintegrated and gender-specific research. Gender-integrated research refers to research happening within the flagship programs (FPs - the main research programs constituting the CRP) and centers of FTA that does not have gender as a primary focus but integrates gender throughout the project cycle. This includes performing gender analyses to inform research design, the collection and analysis of sex-disaggregated data and the presentation of gender findings relevant to the research theme. In contrast, gender-specific research (also referred to as 'strategic gender research' in CGIAR) takes gender relations as an entry point and pursues, as a primary objective, analysis on how gender relations relate to themes of interest to FTA. For instance, such research may focus on innovations that challenge gender norms or policies that limit women's ability to plant trees.

FTA's gender research agenda is positioned within and contributes to FTA's five FPs (Figure 2). It links with gender research occurring within other CRPs and with CGIAR's new GENDER Platform to enhance synergies and amplify contributions to the achievement of the CGIAR gender IDO 'Equity and inclusion achieved'. Gender research is located in geographies relevant to the FP projects, where partnerships with research and boundary partners are leveraged to inform policy and practice.

Using a variety of methodological approaches, including qualitative and quantitative methods, diagnostic and participatory action research, FTA gender research addresses the following key themes:

\section{Participation in restoration and tree management}

FTA identifies and analyzes institutional arrangements that promote the meaningful participation of men and women from different generational groups in decision making related to forest restoration and management. It examines the conditions under which such participation translates into more equitable sharing of benefits and sustainable resource management. This research explores gendered aspirations in communitybased forest management and restoration, identifying key gender-based constraints to the active participation of women and marginalized groups in forest management, codeveloping mechanisms for lifting these constraints and promoting equality through more inclusive forest governance institutions.

\section{Access to delivery systems}

FTA identifies innovative gender-responsive arrangements in delivery systems - in relation to genetic resource management, domestication of tree species and germplasm selection - that are responsive to local gendered knowledge and priorities, improve uptake of forestry and agroforestry technologies and planting material, and create opportunities to foster women's empowerment. FTA analyzes and evaluates innovative approaches to extension and delivery to determine their impacts on women's empowerment and unpack the underlying mechanisms that enable more equal gender relations. 


\section{Value chains and inclusive business models}

FTA identifies structural barriers to smallholder participation and equitable distribution of benefits within global timber, tree crop and select agricultural value chains (i.e. crop drivers of deforestation), as well as strategies to overcome these barriers. This research generates empirical evidence on women's and men's differential access to, and quality of participation within, value chains, their specific challenges to upgrading, and the gender-disaggregated effects of different types of business models on asset and livelihood portfolios. FTA contributes new knowledge and tools to innovate on more inclusive, fair and gender-responsive business and finance models that ensure a sustainable supply of timber and global agro-commodities.

\section{Tenure and local governance}

The program analyzes how gender shapes the devolution of forest rights and responsibilities from states to indigenous and forest-dependent communities, or central to local governments, with some arrangements involving private sector actors. It looks at how this impacts the condition of forests, tenure security and other livelihood outcomes for local women and men and marginalized communities. FTA embeds a gender perspective into its larger body of research on forest tenure by documenting the range of rights that women and men access under different tenure systems (e.g. private, collective, collective on public lands, etc.) identifying actions for securing women's rights, implementing those actions and monitoring their outcomes.

\section{Migration and multi-local livelihoods}

The program identifies and analyzes the types of policies, institutional arrangements and interventions that foster enabling environments for women and men from different generational groups to benefit from migration, mobility and multi-local livelihoods in forested landscapes. FTA assesses the availability and reliability of preexisting data on forests and migration from a gender perspective, and collects additional quantitative and qualitative data on the nexus between forests and migration.

\section{Climate change adaptation and mitigation}

FTA identifies and analyzes the structural causes of gender-differentiated impacts of climate change. It considers how climate change impacts, as well as strategies and interventions to mitigate and adapt to the impacts of climate change, constitute challenges or opportunities to reduce gender gaps in accessing productive resources, redistributing labor burdens and leveling decision-making power. The research incorporates a focus on social differentiation and on the intersecting effects of factors, such as ethnicity, age and socioeconomic status. Knowledge is generated through longterm engagement with local communities in zones targeted for their high vulnerability to climate change. It is disseminated through key partnerships with state and civil society actors.

\section{Policies affecting access to and control over resources}

Cutting across these thematic areas, FTA analyzes sectoral policies and institutional arrangements at different governance levels, and their effects in creating constraining or enabling environments. Research will identify arrangements that promote equitable mechanisms of resource access, which favor women's access to and control over 
forests, trees and other productive resources. This area of study focuses on the synergies - or lack thereof - among sectoral policies in target countries in terms of gender, and recommends ways of harmonizing those policies and mitigating potential trade-offs. It also focuses on institutional arrangements that favor gender-equitable and socially inclusive implementation processes.

The ways in which gender research is embedded within each FP is depicted in Figure 2 and summarized below.

\section{Flagship program 1 - Tree genetic resources to bridge production gaps and promote resilience}

Gender aspects of tree germplasm production and delivery are addressed by exploring the knowledge and preferences of men, women and other social groups with respect to tree species and traits for conservation, domestication and utilization, gender roles in tree management systems, as well as inclusive and gender-responsive delivery systems.

\section{Flagship program 2 - Enhancing how trees and forests contribute to smallholder livelihoods}

Research identifies gendered institutions, constraints and opportunities underpinning decisions and choices over trees, crops, livestock and other livelihood components at household and community levels.

\section{Flagship program 3 - Sustainable value chains and investments for supporting} forest conservation and equitable development

Gender research is operationalized through assessments of the gendered implications of cash-crop expansion and various private commitments, such as zero-deforestation and product certification schemes. Research focuses on analysis of appropriate tools and methodologies that promote inclusive and equitable business models and value chains, highlighting benefit-sharing mechanisms relevant to gender, age and ethnicity aspects, and their use for ensuring sustainable forest development.

\section{Flagship program 4 - Landscape dynamics, productivity and resilience}

Research explores gender-specific decisions and influences over changes in land-use patterns; and the link between gendered livelihoods and expectations of landscape functions. Research in this FP deepens understanding of contexts underpinning men's and women's decisions over land use and landscape management.

Flagship program 5 - Forests, trees and agroforestry for climate change adaption and mitigation

Research addresses gender aspects of producing, transporting and engaging with wood energy, and investigates the differential impacts of emission reduction schemes that prioritize the role of men and women, and indigenous and marginalized communities in forest management. There is a focus on developing recommendations for gender sensitive nationally appropriate mitigation actions (NAMAs) and policy making on Reducing Emissions from Deforestation and forest Degradation (REDD+). 
Figure 2 Gender research across FTA FPs

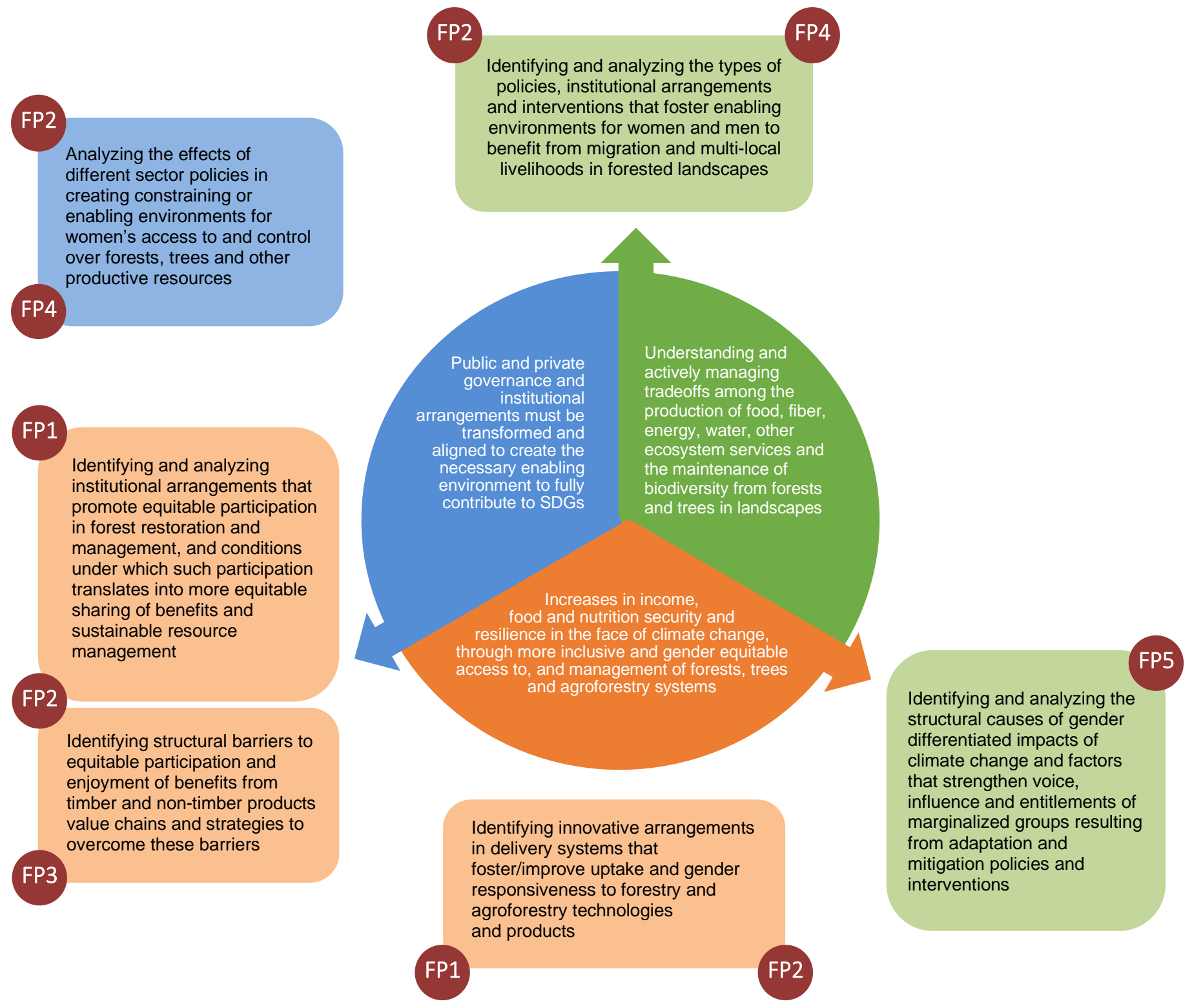

Across the FPs, gender research is embedded within FTA's 25 operational priorities, building on the comparative advantages of FTA and its partners in order to maximize effectiveness and impact. Annex 2 provides illustrative examples. 


\section{Where gender meets generation: Engaging with youth in rural landscapes}

Increasingly, development reports and media cite the so-called global 'youth bulge': the 1.1 billion people between the ages of 15 and 24 (UNDESA 2017), or 1.8 billion people between the ages of 10 to 24 (UNDP 2014), who comprise the most youthful world population to date. Roughly $90 \%$ of these young people live in the developing world (World Bank 2006; UNDP 2014). Asia alone has the majority of the world's young people with India, China and Indonesia holding the largest share of 10-24 year olds (UNFPA 2014). Africa represents the world's youngest region: half the population in sub-Saharan Africa is under the age of 18, and the entire continent has a median age of 25 (UNFPA 2014; AfDB 2016). In addition, as Figure 3 shows, in contrast to the youth population of South and East Asia and the Pacific, the population of youth in Africa is projected to grow.

The majority of these young people live in rural areas and are chronically unemployed or in vulnerable work positions (UNDP 2014; AfDB 2016; Castañeda et al. 2018). These young men and women face a number of work and education challenges, but also have new opportunities in rapidly changing rural to urban spaces. Within these contexts, development discourse and economic outlooks often portray youth as human capital, where they have the potential to be 'agents' and 'makers' of the future, or as 'threats' and 'breakers' of economic downturns and political unrest (Honwana and de Boeck 2005; World Bank 2006; DFID 2016). Either way, figures suggest that the Global South will experience unprecedented challenges in governing and providing for its rising younger population in a substantive and meaningful manner.

Figure 3 Demographic trends for youth in three developing regions of the world
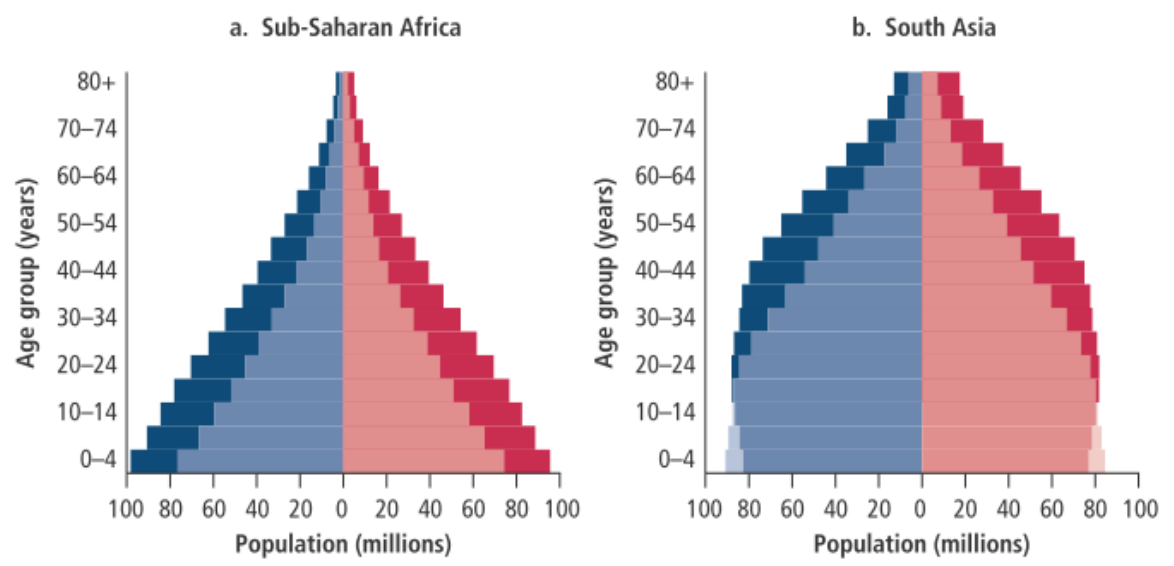

Male 2035

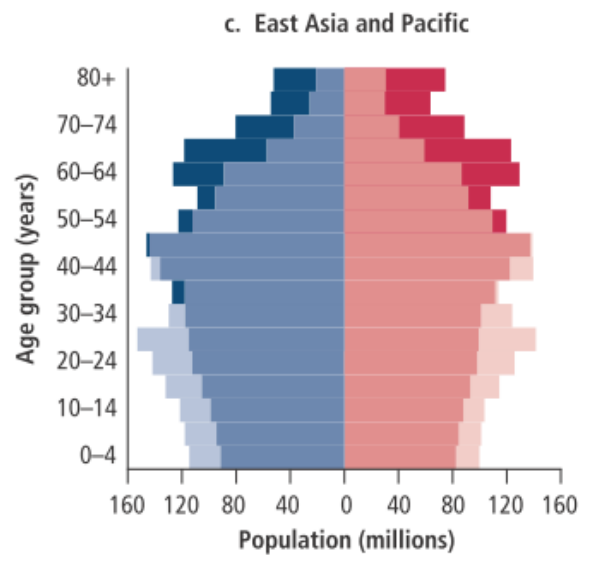

- Female 2035

Source: Filmer and Fox (2014, pg.3) 
Little is known about rural youth's contexts, aspirations, and their changing relationships to rural land and resources. Yet, as young people are a major demographic group in the Global South, their livelihoods will have a fundamental impact on rural lives and the management of landscapes. Hence, at the heart of FTA's mandate for sustainable treebased landscapes and livelihoods are questions such as: what are young generations of rural women and men doing now, and what will they be doing in the future? With what rights and entitlements over resources? Where will they live and with whom? How will their activities and aspirations shape forest and agroforestry landscapes, and how will changes in these landscapes and beyond affect their aspirations and current and future ability to make a living? Four critical issues form the basis for FTA's understandings of, and engagement with, youth.

\section{Heterogeneity of 'youth' and young people's experiences}

There is great diversity within 'youth'. Numerous factors - including gender, age and stage in life cycle - which take different meanings across social, cultural and political contexts, inform how a society might define and treat 'youth'. In this way, 'youth' is a relational category, where one must understand the larger social relations that inform, affect and define young people. A relational approach to studying young people means understanding the wider social relations, in the households and societies within which they are embedded. These relations, and the multiple factors which mediate them, shape their access to information, land, natural resources and values, as well as their abilities to access education, jobs and capital. Although it distinguishes the structures within which rural youth are embedded, a relational approach also recognizes personal agency among young people, as well as within the networks that influence them, such as their peers and family. Hence, FTA takes a relational approach to studying 'youth' as a social factor that intersects with gender and other factors of social differentiation. Explicitly considering intergenerational relations helps recognize rural young people's current and future challenges and opportunities in FTA's FP areas.

\section{Migration and off-farm livelihoods}

As urban and rural landscapes and land uses have changed, so have the demands for urban and rural labor. Although geographically specific and uneven, the last few decades have seen increased regional and international trends in migration and mobility between and within rural-urban and transnational spaces, with the largest movements in Asia (World Development Indicators, 2017). Studies in Africa and Southeast Asia, for example, note changes occurring in rural areas, such as how many households reflect more urban (than rural) ways of living, through patterns in consumerism, off-farm work and mobility (Bryceson 1996; Kelly 2011; Rigg et al. 2012). Rural livelihoods are becoming delocalized as new, intensifying forms of mobility and migration involve daily, temporary, or permanent moves of working age, and increasingly younger, household members to other national and international locations (UN 2017, 16). Different types of migration carry distinct livelihood implications. Changes in family structure and locations influence visions for and the management of forest and agroforestry systems. 


\section{Formal education, an aspiration-achievement gap, and changing relations to land and labor}

These labor movements, accompanied by shifting values and, in many areas, increased household incomes have led many rural families to place greater investments in formal education, such that today's younger generations have, on average, more years of schooling than generations before. Intergenerational, socioeconomic and cultural changes have not only altered the physical form and functions of households but have fundamentally transformed rural youth's social relationships to land and rural life. Historical changes in labor, agricultural and off-farm work practices, and poor terms of trade for most agricultural products, along with shifting values linked to media and greater time in school, have contributed to many young people's disinterest in rural work. Moreover, the lack of emphasis on and value given to agriculture in primary and secondary school curricula, as well as outdated agricultural curricula where they do exist, have failed to support the skills or interest of youth in agriculture. In fact, many rural young people (and families) see rural work as a last resort, as broader sociocultural changes have devalued forest and farm work. Some authors caution, however, that rural young people - particularly young men - do not altogether reject agricultural livelihoods, but rather agriculture that is low-return, labor-intensive and lacking in the use of modern knowledge and technology (Anyidoho et al. 2012; White 2012; Kristensen and Birch-Thomson 2013; Ameur et al. 2015; El Hassane et al. 2015; Elias et al. 2018). In most countries of the Global South, however, aspirations pertaining to formal, skilled blue- and white-collar jobs stand in contrast with the few formal (government or private sector) employment opportunities and the predominance of the informal sector (White 2012; Leavy and Hossein 2014). This aspiration-attainment gap has been widely reported in Africa (Kritzinger 2002; Leavy and Smith 2010; Chinsinga and Chasukwa 2012) and other regions of the Global South (White, 2012). Understanding young people's aspirations and employment prospects, as well as how rural households invest in younger generations, whether through migration, education, land or other means, highlights key challenges and opportunities for the involvement of future generations in tree and forest management.

\section{Youth-specific versus generalized rural development constraints and opportunities}

It is well known that young people in rural areas experience particular resource constraints, including limited access to land (amid increasing scarcity and costs of land, and delayed intergenerational transfers of land from parents or relatives), technology, knowledge and financial resources. While some such constraints apply disproportionately to young people (e.g. limited networks), others apply to rural dwellers more generally; for example, as rural dwellers in the Global South commonly have inadequate infrastructure and face isolation from markets and challenges accessing credit. Young people thus participate in the larger ups and downs of rural development. There is great heterogeneity in these processes, rates of change and consequences for different groups of rural dwellers. Hence, creating opportunities for youth in rural landscapes is inscribed in the larger challenge of rural economic development, within which additional measures may be required to ensure that young people - both women and men - are equitably able to access emerging opportunities. 
Several programs now focus on 'youth-specific' programming to create employment or capacity-strengthening opportunities that specifically target young people (see FAO et al. 2014, for example). Yet, there are often mismatches between rural young people's own aspirations and what these programs can deliver in terms of skills development or employment (FAO et al. 2014; Ayele et al. 2017). What is more, they often have a focus on entrepreneurship while, despite having some level of formal education, many rural youth, and particularly young women, lack the skills, credit, information and experience to run an enterprise, and may not be interested in such a precarious business. Finally, given the broad social diversity that exists among youth, any rural development approach that applies a 'one-size fits all' strategy to rural youth, such as entrepreneurship, will not match the current skills, abilities and resources of many young people living in remote or marginal areas.

Hence, there is a need to address the socioeconomic contexts where young people live, rather than simply the skills-for-employability of young people with the assumption that there are formal sector jobs available for prepared young people (UNDESA 2019). It also critical to recognize that young people's aspirations are far broader than employment attainment, and to value and support their ability to achieve what they value for their own development and that of their communities (UNDESA 2019).

\section{A youth research agenda for FTA: A relational approach to studying youth and researching with young people}

In light of the issues discussed above, FTA takes a relational approach that engages with the wide range of economic, societal and cultural factors that shape the use and management of land and forests; and with the everyday lives of families and young people who live in rural areas and are rarely heard. Taking an overview of different regions must be coupled with consideration of the specificities of the localities and of the different types of production systems where FTA works for more in-depth analyses. For instance, the experiences of rural young people may vary greatly from more traditional production systems in isolated areas to 'modern' systems using new technologies, new or greatly expanded production of specific crops/products (palm oil, cocoa, coffee, nuts), value chains or markets.

FTA's research on youth sits within its gender equality and social inclusion research agenda, and is rooted in an analysis of the dynamic social relations and agrarian structures that shape rural people's capacities to lead the lives they wish to live in (and often beyond) tree-based landscapes (CGIAR FTA 2017). The research follows two interrelated perspectives. The first focuses on young women's and men's aspirations, interests, knowledge and skills in relation to forest and agroforestry landscapes and livelihoods. The second generates evidence around the structural and institutional factors that enable or constrain young women's and men's engagement in tree and forest management, and in entrepreneurial activities and value chains across the forest transition curve. These factors include their commonly limited access to decisionmaking spaces and productive resources, such as land, finance and information, which constrain their capacity to make a living and innovate. Within both streams, the research contributes to the development of tools, approaches and measures that can support young men's and women's capacities, interests and opportunities in forest and agroforestry landscapes. Table 1 in Annex 1 shares some key youth research questions and ongoing activities related to FTA, as identified by the FTA director, FP and 
Monitoring, Evaluation, Learning and Impact Assessment (MELIA) leaders during the preparation of this document. 


\section{Impact pathways}

As explained in section 3, the FTA Gender Strategy follows a multi-pronged approach, characterized by two main strands of work. Whereas the first strand centers on producing good quality gender research and knowledge generation as described above, the second focuses on strengthening gender integration along FTA's impact pathways, including how the program engages with a wide range of stakeholders (e.g. other researchers, practitioners, decision-makers, policymakers, etc.). This is achieved through:

(i) Capacity development to equip scientists and partners with the latest approaches and good practices in gender and NRM, and with the skills to identify how social differentiation influences opportunities, constraints and interests across FTA's thematic research priorities. This is partly achieved through training, peer-to-peer learning, targeted support to project teams, and the creation of frameworks, tools and methods for gender analysis and gender-responsive work. These tools are designed for FTA scientists, as well as other researchers, practitioners, and policy makers working on FTA-related issues. This contributes to the legitimacy of the research produced in FTA (see ISDC 2017).

(ii) Outreach and knowledge sharing to enhance the visibility and support awareness and uptake of FTA's gender research by various audiences, positioning FTA as the go-to place for salient and credible research on gender and forestry. This is achieved through knowledge-sharing platforms, communities of practice, and various gender-specific communication products targeted at specific audiences and forums. To enhance its influence in various policy processes, FTA synthesizes gender research findings into targeted submissions to be featured in relevant global publications or to inform specific policy processes. The program invests in hosting global, regional and national events featuring FTA gender research and researchers, and targets various global environmental and feminist forums. FTA also partners with the Global Landscapes Forum and other strategic partners to organize targeted events and workshops at national and regional levels.

(iii) Strategic partnerships and targeted engagement strategies to advocate for evidence-based, gender-responsive innovations as well as to deepen the quality and implementation of FTA gender research. This is a key element of the impact pathways of the different FPs and of the overall FTA program. FTA's boundary partners include a wide range of actors, including government ministries, donors, UN agencies and multilateral bodies, policy platforms, international nongovernmental organizations, research organizations, and various non-governmental organizations and advocacy bodies. Through actively building and maintaining relationships with our boundary partners, and establishing and coordinating communities of practice on gender across FTA's thematic focus areas, FTA aims to increase uptake of evidence-based recommendations while better aligning its work with partners' needs and priorities. Through partnerships with renowned academics working at the nexus of gender and the environment, FTA aims to both incorporate cutting-edge feminist and gender theories into FTA research and to influence academic discourses on the topics on which FTA works. FTA also collaborates with various national and local partners to enhance the co-production of knowledge and building the capacity of national partners to address gender issues in their work. 
(iv) Adaptive learning and gender-responsive monitoring, learning and evaluation, to support teams (including the MELIA team of FTA) in understanding change processes and/or in the design and tracking of indicators that measure outcomes in terms of gender equality. These may include changes in the status and roles of women and men, in norms, attitudes and behavior, in the benefits and costs perceived by different social groups (including in terms of labor and time), effective participation in planning and decision-making processes, property rights, access to technologies and services, income distribution, and market access. The focus of such monitoring is twofold: (i) to identify which specific types of interventions support or foster greater equality between men and women of different ages and sociocultural backgrounds in forests and agroforestry landscapes; and (ii) to monitor progress and contributions toward sub-IDOs 1 and 3.

This strengthening strand is both inward- and outward-looking with respect to FTA. It involves 'getting our house in order' to value and strengthen capacities for delivering a high volume of quality, impactful research that will foster gender equality as well as other sought FTA outcomes. It also entails building partnerships across the CRPs and beyond to mainstream gender in discourses (e.g. around restoration, climate change or inclusive business models) and multilateral environmental agreements and agendas (e.g. Rio Conventions) of concern to FTA.

The gender strengthening and research strands are interrelated and mutually reinforcing (Figure 1). Maintenance of strong FTA processes and gender research capacities is required to produce cutting-edge, theory-building gender research as well as topical, policy-relevant gender analysis. Investing in strengthening and building this capacity will produce a stronger body of work through which to engage in academic debates as well as influence policy and practice. Likewise, evidence generated through research will underpin FTA's engagement with external partners, and with the discourses and international agendas of interest to FTA. In this way, this research and action agenda offer a pathway for transformative change toward more equitable and sustainable forest, tree and agroforestry systems. 


\section{References}

[AfDB] African Development Bank. 2016. Jobs for youth in Africa: Catalyzing youth opportunity across Africa. Abidjan: African Development Bank.

Agarwal B. 2010. Gender and Green Governance: The Political Economy of Women's Presence Within and Beyond Community Forestry. New Delhi and Oxford: Oxford University Press.

Agarwal B. 2001. Participatory exclusions, community forestry, and gender: An analysis for South Asia and a conceptual framework. World Development 29(12):1623-1648.

Ameur F, Quarouch H, Dionnet M, Lejars C and Kuper M. 2015. Outiller un débat sur le rôle des jeunes agriculteurs dans une agriculture en transition dans le Saïss (Maroc). Cahiers Agricoles 24:363-371.

Anyidoho NA, Kayuni H, Ndungu J, Leavy J, Sall, M, Tadele G and Sumberg J. 2012. Young people and policy narratives in sub-Saharan Africa. FAC Working Paper 32. Brighton, UK: Future Agricultures Consortium.

Ayele S, Khan S and Sumberg J, eds. 2017. Africa's youth employment challenge: New perspectives. IDS Bulletin 48(3):1-12.

Barrientos S. 2001. Gender, flexibility and global value chains. IDS Bulletin 32(3):83-93.

Bee BA. 2016. Power, perception, and adaptation: Exploring gender and social environmental risk perception in northern Guanajuato, Mexico. Geoforum 59:71-80. http://blog.ecu.edu/sites/beeb/files/2016/04/Geoforum RG.pdf

Brody A, Demetriades J and Esplen E. 2008. Gender and Climate Change: Mapping the Linkages. A Scoping Study on Knowledge and Gaps. Brighton, UK: BRIDGE, Institute of Development Studies (IDS). http://www.bridge.ids.ac.uk/sites/bridge.ids.ac.uk/files/reports/Climate Change DFID.pdf

Bryceson D. 1996. Deagrarianization and rural employment in sub-Saharan Africa: A sectoral perspective. World Development 24(1):97-111.

Castañeda A, Doan D, Newhouse D, Nguyen MC, Uematsu H and Azevedo JP. 2018. A new profile of the global poor. World Development 101:250-267.

[CGIAR FTA] CGIAR Research Program on Forests, Trees and Agroforestry. 2017. Gender equality and social inclusion. Accessed 15 December 2017. http://foreststreesagroforestry.org/gender-equality-and-social-inclusion/

Chinsinga B and Chasukwa M. 2012. Youth, Agriculture and Land Grabs in Malawi. Conference paper, Young People, Farming and Food, 19-21 March 2012, Accra, Ghana.

Cole SM, Kantor P, Sarapura S and Rajaratnam S. 2014. Gender-transformative approaches to address inequalities in food, nutrition and economic outcomes in aquatic agricultural systems. Working Paper: AAS-2014-42. Penang, Malaysia: CGIAR Research Program on Aquatic Agricultural Systems.

Coleman EA and Mwangi E. 2013. Women's participation in forest management: A crosscountry analysis. Global Environmental Change 23(1):193-205.

Colfer CJP, Sijapati Basnett B and Ihalainen M. 2018. Making sense of 'intersectionality': A manual for lovers of people and forests. Occasional Paper No. 184. Bogor: Center for International Forestry Research (CIFOR).

[DFID] Department for International Development. 2016. Putting young people at the heart of development: The Department for International Development's Youth Agenda. London: DFID. 
Djoudi $\mathrm{H}$ and Brockhaus M. 2011. Is adaptation to climate change gender neutral? Lessons from communities dependent on livestock and forests in northern Mali. International Forestry Review 13(2):123-135. https://cgspace.cgiar.org/handle/10568/20856

El Hassane A, Kadiri Z, Kuper M and Quarouch H. 2015. Composer avec l'État: voies d'engagement des jeunes diplômés dans l'agriculture au Maroc. Cahiers Agricultures 24:356-362.

Elias M, Mudege N, Lopez DE, Najjar D, Kandiwa V, Luis J, Yila J, Tegbaru A, Ibrahim G, Badstue L, Njuguna-Mungai E and Bentaibi A. 2018. Gendered aspirations and occupations among rural youth, in agriculture and beyond: A cross-regional perspective. Journal of Gender, Agriculture and Food Security 3(1):82-107.

European Commission. 2011. Toolkit: Gender in EU-funded research. Luxembourg: Office for Official Publications of the European Communities.

[FAO] Food and Agriculture Organization. 2011. The State of Food and Agriculture 2010-2011. Women in Agriculture: Closing the gender gap for development. Rome: FAO.

[FAO, CTA and IFAD] Food and Agriculture Organization, Technical Centre for Agricultural and Rural Cooperation and the International Fund for Agricultural Development. 2014. Youth and agriculture: Key challenges and concrete solutions. Rome: Food and Agriculture Organization of the United Nations.

Filmer D and Fox L. 2014. Youth Employment in Sub-Saharan Africa. Africa Development Forum. Washington, DC: World Bank and Agence Française de Développement.

Gumbo DJ, Moombe KB, Kandulu MM, Kabwe G, Ojanen M, Ndhlovu E and Sunderland TCH. 2013. Dynamics of the charcoal and indigenous timber trade in Zambia: A scoping study in Eastern, Northern and Northwestern provinces. Occasional Paper 86. Bogor: Center for International Forestry Research (CIFOR).

Hillenbrand E, Karim N, Mohanraj P and Wu D. 2015. Measuring gender transformative change: A review of literature and promising practices. Working Paper. Atlanta, GA: CARE USA.

Honwana A and De Boeck F. 2005. Makers and Breakers: Children and Youth in Postcolonial Africa. Oxford: James Currey Press.

Ingram V, Haverhals M, Petersen S, Elias M, Basnett BS and Sola P. 2016. Gender and forest, tree and agroforestry value chains: Evidence from the literature. In Colfer CJP, Basnett BS, and Elias M, eds. Gender and Forests: Climate Change, Tenure, Value Chains, and Emerging Issues. London: Earthscan. 221-242.

Ingram V, Schure J, Chupezi Tieguhong J, Ndoye O, Awono A, and Midoko Iponga D. 2014. Gender implications of forest product value chains in the Congo basin. Forests, Trees and Livelihoods 23(1-2):67-86.

[ISPC] CGIAR Independent Science and Partnership Council. 2017. Quality of research for development in the CGIAR context. Brief No. 62. Montpellier, France: ISPC. Accessed 30 March 2020. https://cas.cgiar.org/sites/default/files/pdf/ispc brief 62 qord.pdf

Kelly P. 2011. Migration, agrarian transition and rural change in Southeast Asia: Introduction. Critical Asian Studies 13(4):479-506.

Kristensen S and Birch-Thomson T. 2013. Should I stay or should I go? Rural youth employment in Uganda and Zambia. International Development Planning Review 35(2):175201.

Kritzinger A. 2002. Rural youth and risk society: Future perceptions and life chances of teenage girls on South African farms. Youth \& Society 33(4):545-572.

Lambrou Y and Piana G. 2006. Gender: The missing component of the response to climate change. Rome: FAO. 
Leavy $\mathrm{J}$ and Hossain N. 2014. Who wants to farm? Youth aspirations, opportunities and rising food prices. IDS Working Paper 439. Brighton, UK: Institute of Development Studies.

Leavy J and Smith S. 2010. Future farmers: Youth aspirations, expectations and life choices. Discussion Paper 013. Brighton, UK: Future Agricultures Consortium.

McDermott MH. 2008. Locating benefits: Expanding decision-spaces, resource access and equity in US community-based forestry. Geoforum 40(2):249-259.

McLain R, Lawry S, Guariguata MR and Reed J. 2018. Toward a tenure-responsive approach to forest landscape restoration: A proposed tenure diagnostic for assessing restoration opportunities. Land Use Policy. https://www.sciencedirect.com/science/article/pii/S0264837718303855

Mwangi E, Meinzen-Dick R and Sun Y. 2011. Gender and sustainable forest management in East Africa and Latin America. Ecology and Society 16(1): 17. https://www.ecologyandsociety.org/vol16/iss1/art17/

Nederlof $S$ and Dangbégnon C. 2007. Lessons for farmer-oriented research: Experiences from a West African soil fertility management project. Agriculture and Human Values 24(3):369_ 387.

Rigg J, Salamanca A and Parnwell M. 2012. Joining the Dots of Agrarian Change in Asia: A 25 Year View from Thailand. World Development 40(7):1469-1481.

Rodenberg B. 2009. Climate change adaptation from a gender perspective. A cross-cutting analysis of development-policy instruments. Discussion paper. Bonn: Deutsches Institut für Entwicklungspolitik (DIE). https://www.die-gdi.de/uploads/media/DP 24.2009.pdf

Sijapati BB, Gynch S and Anandi CAM. 2016. Transforming the Roundtable on Sustainable Palm Oil for Greater Gender Equality and Women's Empowerment. CIFOR InfoBrief No.166. Bogor, Indonesia: Center for International Forestry Research (CIFOR).

Sun Y, Mwangi E and Meinzen-Dick R. 2011. Is gender an important factor influencing user groups' property rights and forestry governance? Empirical analysis from East Africa and Latin America. International Forestry Review 13(2):205-219.

Sunderland TCH, Achdiawan R, Angelsen A, Babigumira R, Ickowitz A, Paumgarten F, ReyesGarcia V and Shively G. 2014. Challenging perceptions about men, women, and forest product use: a global comparative study. World Development 64(Supplement 1):S56-S66.

Turner B. 2014. Neoliberal Politics of resource extraction: Moroccan argan oil. Forum for Development Studies 41(2):207-232.

[UN] United Nations 2017. International Migration Report. Highlights (ST/ESA/SER.A/404). Geneva: Department of Economic and Social Affairs, Population Division.

[UNDESA] United Nations Department of Economic and Social Affairs. 2019. World Population Prospects 2019: Highlights. New York: UNDESA.

[UNDESA] United Nations Department of Economic and Social Affairs. 2017. World Population Prospects: The 2017 Revision, Key Findings and Advance Tables. Working Paper No. ESA/P/WP/248. New York: UNDESA.

[UNDP] United Nations Development Programme. 2014. Empowered Youth, Sustainable Future. UNDP Youth Strategy 2014-2017. New York: UNDP.

[UNEP, FAO and UNDP] United Nations Environment Programme, Food and Agriculture Organization of the United Nations and United Nations Development Programme. 2011. The UN REDD Programme Strategy 2011-2015. Geneva: UN-REDD Programme Secretariat.

[UNFPA] United Nations Population Fund. 2014. State of World Population: The power of 1.8 billion: Adolescents, youth and the transformation of the future. New York: UNFPA. 
White B. 2012. Agriculture and the generation problem: rural youth, employment and the future of farming. IDS Bulletin 43:6.

World Bank. 2006. World development report 2007. Development and the next generation. Washington, DC: The International Bank for Reconstruction and Development/The World Bank.

World Bank. 2017. World Development Indicators. Washington, DC: World Bank. Accessed: 20 May 2019. http://wdi.worldbank.org/table/3.1

[WB, FAO and IFAD] World Bank, Food and Agriculture Organization and International Fund for Agricultural Development. 2009. Gender in Agriculture Sourcebook. Agriculture and Rural Development. Washington, DC: World Bank. 


\section{Annex 1 Key youth-related research questions for FTA}

Table 1 Integrating youth perspectives in FTA

Key youth research questions

\section{Areas for further youth outreach and} capacity development

FTA-wide

1. What are the specific tree and forest sectors in which those involved are aging? Why are young people moving away from these sectors, and what are their characteristics?

2. Are young men and women interested in participating in tree or forest-based enterprises? What are the skills and incentives required to enable them to do so?

3. How do young people who work in rural sectors access land and resources, including trees and non-timber forest products? How are benefits distributed across generations and among young people? How are young women and men positioned within rural institutions and forest and land governance?

4. How will agroforestry and local ecological knowledge linked to cultural patterns be maintained and reproduced as many young people leave their villages and rural areas?

5. To what extent are sectoral policies incorporating youth concerns and allowing for participation of youth?

6. Which sectors and tree-based value chains are more successful in incorporating youth concerns and allowing for their participation?

- Longer-term studies that examine the generational changes in communities' forestry and agroforestry knowledge and practice.

- Research to identify the needs, gaps and interests of young women and men with respect to training/education and work in each FP.

- Research on integration of intergenerational considerations in sectoral policies. 


\section{Flagship program 1: Tree genetic resources to bridge production gaps and promote resilience}

1. What types of tree crops and production techniques are young women and men interested in and why? What tree, crop and forestry training is available, missing and/or needed in school curricula?

2. How can training be integrated with available information and communication technologies (ICTs) to make tree crops and agroforestry attractive for young people?
- Research to identify successful regional farms and/or field schools working with young women and men to raise seedlings, domesticate strong varieties, and/or create local products.

- Creating more education and funding support for youth education in the use and production of fruit trees.

\section{Flagship program 2: Enhancing how trees and forests contribute to smallholder livelihoods}

1. What are the roles of young people in contributing to their household's or family's livelihoods, and how is this affected by gender and stage in the life cycle?

2. What are young men and women's interests in producing and marketing FTA products?
- Research to identify the actors and institutions that can support more technology and training for young people's production and marketing of trees and crops.

- Research on young men's and women's skills and capacity development needs in regards to production, marketing and technology; and research on the availability of markets for FTA products of interest to young men and women.

\section{Flagship program 3: Sustainable value chains and investments for supporting forest conservation and equitable development}

1. What are the challenges and opportunities that different youth face in accessing FTA markets and information? How can markets work better for young women and men?

2. What are the life histories and contexts of young people working in oil palm, timber and other FTA commodity sectors? How long do they work in these activities, and what is their relationship to their natal village lands?
- Research on young men's and women's interests and engagement in regional supply chains, including the availability of markets and access to information (by gender).

- Research on alternative land-use arrangements for young people when land is scarce and/or difficult to access (e.g. out-grower schemes). 
1. How are land uses and labor dynamics evolving as young people and household members pursue more multi-local livelihoods?

2. How do local forest enterprises, agroforestry or agribusiness investments affect the dynamics of youth employment and migration in surrounding rural communities?

3. To what extent are youth organizations/mobilizations emerging around natural resources?
- Longer-term studies that examine the effects of rural economic diversification and youth migration on land uses and labor dynamics in rural areas.

- Research that examines how young women and men are included in agroforestry and agribusiness decision making and the governance of landscapes.

\section{Flagship program 5: Forests, trees and agroforestry for climate change adaptation and mitigation}

1. How does climate change factor into the livelihood and migration decisions of rural households and their young women and men?

2. What are the opportunities for young women and men in the bioenergy sector? What are the related trainings and skills rural youth need, and what are the available technologies?
- Research on the available rural and urban opportunities for young women and men in renewable energy/climate change sectors and on the skills needed to fill these roles.

\section{Monitoring, evaluation, learning and impact assessment (MELIA)}

1. How are diverse groups of young people integrated and engaged in project planning, development and implementation of activities?

2. What indicators are needed to track progress toward improving the equitable inclusion of young people in FTA development processes?
- Research on project design frameworks and methods that successfully integrate social dynamics (gender, youth, etc.) into project phase development, planning and implementation. 


\section{Annex 2 Gender research embedded in FTA's operational priorities}

Priority \#1 (Restoration): Gender research centers on developing the empirical evidence base through cross-country, comparative analyses on gender in restoration, with a link to the cost-benefit research stream; knowledge sharing, partnerships and outreach through a gender constituency in the Global Landscapes Forum, collaboration with country governments (e.g. Kenya) and communications products.

Priority \#2 (Plantations and tree crop commodities): Gender work on tree crops focuses on assessing gender roles, constraints, and the differential impacts of production and various forms of trade in high value tree crops on producers to promote gender-equitable opportunities and sharing of costs and benefits. Emphasis is on cacao and oil palm, two of the main commodities of interest to FTA due to their significance for livelihoods and rapid land-use change.

Priority \#3 (Enhanced nutrition and food security): Gender research focuses on fruit tree portfolios and agrobiodiversity to explore links between food choices, gendered preferences and intra-household dynamics and how these impact nutrition outcomes.

Priority \#4 (Safeguarding, biodiversity and conservation): Gender research examines local management of priority tree species, including gendered knowledge and skills required to maintain priority species across the farm to forest continuum.

Priorities \#5 (Nationally determined contributions) and \#8 (Climate change adaptation): Research focuses on the gendered impacts of climate change mitigation policy and action, including REDD+. It also examines the gender dimensions and implications of national and provincial climate change adaptation programs and policies.

Priority \#9 (Landscape governance): Gender work on landscape governance focuses on how to reconcile different priorities and strategic interests in resource management at the landscape scale, on secure and gender-equitable access to and control of land and natural resources, and on how to meaningfully include women and marginalized groups in landscape or forest governance decisions.

Priority \#12 (Market-based agroforestry-forestry): Gender research on market-based agroforestry develops the evidence base on integrated landscape management and market systems that can provide better returns from the sale of agroforestry products for all the small-scale actors involved. The focus is on identifying management practices, processing and market opportunities that support the empowerment of women and the equitable sharing of benefits.

Priority \#15 (Livelihood trajectory modeling and assessment): Gender work on livelihood trajectories has mainly focused on migration dynamics and their effects on NRM, and vice versa. It includes work on aspirations of rural young men and women in NRM or agriculture, which aims to develop initiatives that respond to the priorities and capacities of young people and lead to sustainable livelihood and land-use options. An enhanced understanding of rural household aspirations, and the gender dynamics that influence them, will also have implications for targeting and scaling of agricultural innovations.

Priority \#16 (Inclusive finance and business models): This research stream assesses the gender-responsiveness of standards for fair trade and different certification systems. This work will contribute to understanding gender norms within 
value chains, barriers to entry, and gender dynamics around production nodes where interventions may lead to broader distribution of benefits.

Priority \#18 (Public and private commitments to zero deforestation): Gender work in this priority mainly focuses on the rights of indigenous peoples and women, and to gender analyses with respect to jurisdictional approaches to zero deforestation. 


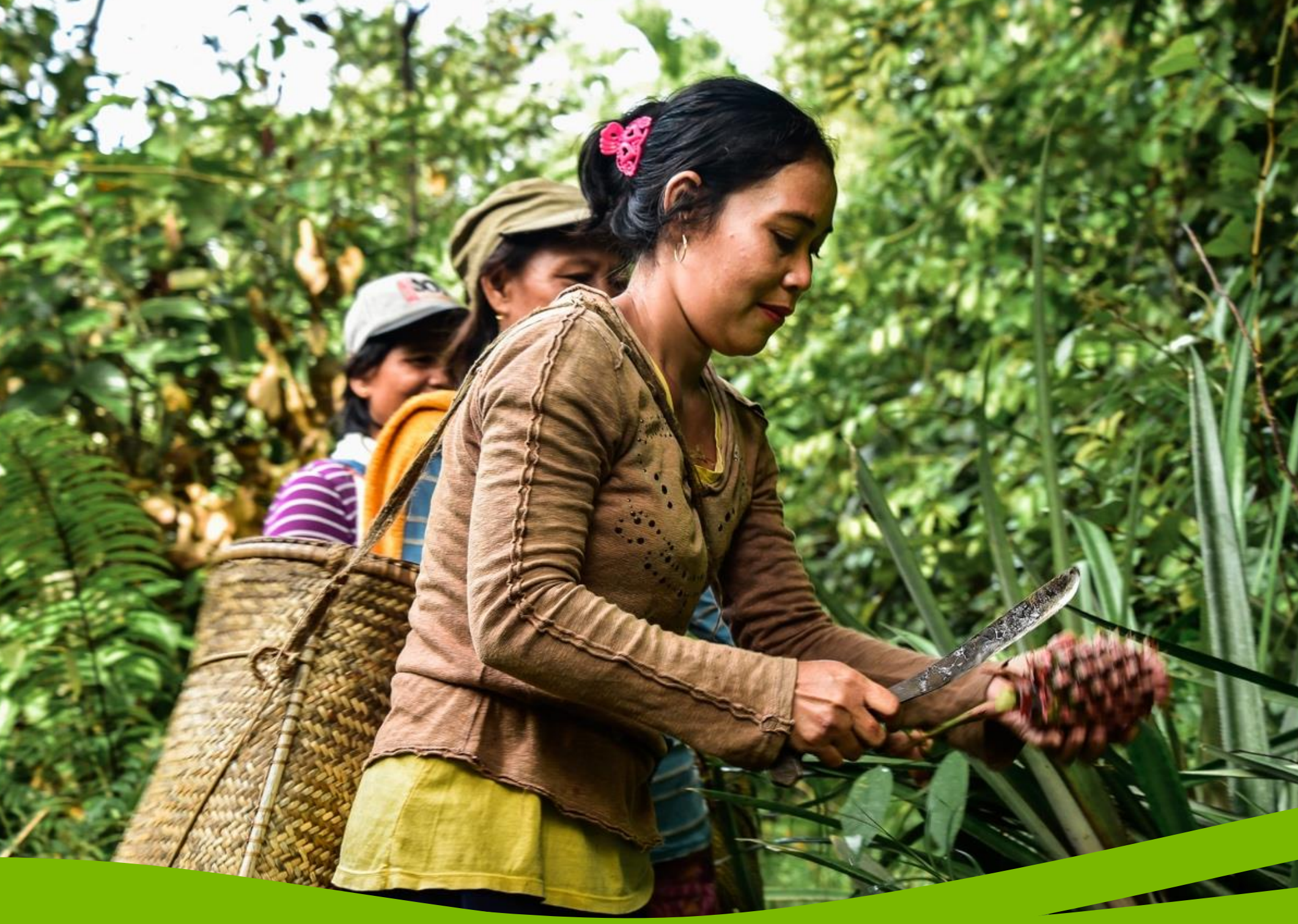

Cover photo: Female members of the Binayi Community Forest User Group, Nepal. Photo by Chandra Shekhar Karki/CIFOR. Back photo: Ibu Rosalina cutting nanas (pineapples) in Bogor, Kapuas Hulu, West Kalimantan, Indonesia. Photo by lcaro Cooke Vieira/CIFOR

The CGIAR Research Program on Forests, Trees and Agroforestry (FTA) is the world's largest research for development program to enhance the role of forests, trees and agroforestry in sustainable development and food security and to address climate change. CIFOR leads FTA in partnership with Bioversity International, CATIE, CIRAD, ICRAF, INBAR and $\mathrm{TBI}$.

FTA thanks all the donors who supported this research through their contribution to the CGIAR Trust Fund: cgiar.org/funders/

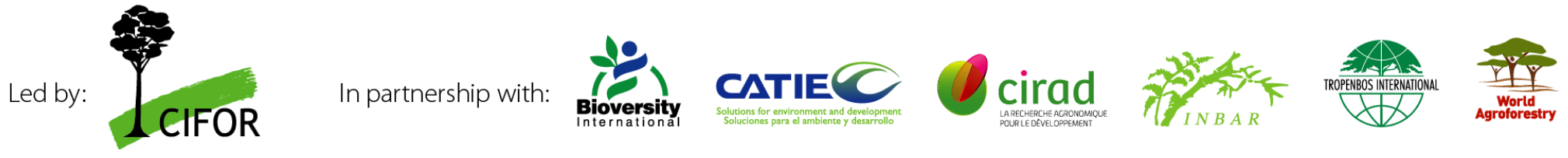

(b) RESEARCH PROGRAM ON

Forests, Trees and Agroforestry
(3) foreststreesagroforestry.org

$\checkmark$ cgiarforestsandtrees@cgiar.org y aFTA_CGIAR

f foreststreesagroforestry 